\title{
Evidence of hydrogen ion secretion from the human gall bladder in vitro
}

\author{
J N Plevris, P C Hayes, D J Harrison, I A D Bouchier
}

\begin{abstract}
Gall bladder bile is more acid that hepatic bile and this has been attributed to bicarbonate absorption by the gall bladder epithelium. The aim of this study was to investigate in vitro the acid base changes that occur across the human gall bladder mucosa. Fresh gall bladder tissue was obtained at cholecystectomy and placed in an Ussing Chamber and perfused with RingerKrebs glucose bicarbonate solution. The viability of the gall bladder was assessed by measuring the potential differences across the epithelium and by the morphology of the epithelial cells at the end of the experiments. Aliquots from the solutions were taken at two, 45 and 70 minutes and $\mathrm{pCO}_{2}$, hydrogen ion and bicarbonate concentrations were measured. In the mucosal side of the chamber a consistent and significant decrease was observed from two minutes to 70 minutes in bicarbonate concentration while $\mathrm{pCO}_{2}$ and hydrogen ion concentrations significantly increased. The degree of inflammation correlated well with the ability for acidification, the more inflamed the tissue the less its ability to acidify. When the gall bladder was exposed to amiloride or sodium free solution acidification was abolished in the mucosal side. When tissue metabolism was irreversibly inhibited by exposure to formaldehyde, hydrogen ion concentration and $\mathrm{pCO}_{2}$ were significantly decreased in the mucosal side of the chamber compared with the viable gall bladder. The human gall bladder is capable of secreting acid and this may be an important mechanism for preventing calcium precipitation and gall stone formation.
\end{abstract}

Gall stone disease is a common cause of morbidity and mortality and cholocystectomy represents a significant percentage of major upper abdominal operations in western society. Although considerable research has been concentrated on the pathogenesis of gall stone formation, this has often focused on the biochemical changes that occur in the bile. It is only within the last 10 years that the importance of the events in the gall bladder and in particular the possible contributions of the gall bladder mucosa to lithogenesis has been recognised.

The gall bladder mucosa has one of the highest rates of water absorption in the body and an 80 to $90 \%$ decrease in the initial volume of bile is achieved within the gall bladder. This is

Part of this work has been presented at the British Society of Gastroenterology Autumn Meeting, Sheffield 1988, and has been published as an Abstract in Gut (October 1988). achieved by coupling of active sodium transport and passive water absorption resulting in isotonic fluid absorption. ' Fluid transport is subject to physiological regulation and is higher in the daytime. ${ }^{23}$ Electrolyte transport has been extensively investigated and chloride is actively absorbed in exchange for bicarbonate. ${ }^{+}$Potassium moves passively from the mucosa to the serosa according to electrochemical gradients, ${ }^{5}$ and calcium is also absorbed and its distribution across the gall bladder epithelium is consistent with passive transport. ${ }^{6}$ Its contribution to gall stone formation is increasingly recognised. Most of the organic components of bile - namely, bile acids, lecithin, bilirubin, and cholesterol are absorbed to a limited degree by the human gall bladder mucosa. ${ }^{58}$ There is more recent evidence that the human gall bladder has not only absorptive but also secretory properties. Fluid absorption can be reversed to net secretion with feeding in chronic inflammation or with the use of pharmacological agents (prostaglandins, prostacyclin, gut hormones, etc). ${ }^{9}$ An increasing number of biliary proteins are known to be secreted from the gall bladder mucosal cells such as mucin, immunoglobulins, etc. ${ }^{10-12}$ In man as well as in other species there is decline in the $\mathrm{pH}$ of the gall bladder bile compared with hepatic bile. Initially this was thought to be the result of bicarbonate reabsorption by the gall bladder mucosa. ${ }^{1-5}$ Studies in rabbit, guinea pig, and necturus gall bladders have produced evidence for mucosal hydrogen secretion during sodium reabsorption, probably representing a sodium/ hydrogen exchange. ${ }^{13-17}$ In a more recent study it has been suggested that the canine gall bladder has the ability to secrete hydrogen ions in vivo. ${ }^{18}$ There are, however, no studies on the human gall bladder mucosa dealing with the mechanisms of bile acidification and it is not clear whether this is because of hydrogen ion secretion or bicarbonate reabsorption. Acid secretion by the gall bladder has important implications for gall stone formation because the majority of gall stones contain calcium carbonate and changes in the $\mathrm{pH}$ of the bile are of critical importance in influencing the calcium solubility in bile. ${ }^{18} 19$

The present study was undertaken to investigate the role of the gall bladder epithelium in the acidification process of bile in vitro using fresh viable human gall bladder mucosa obtained at cholecystectomy.

\section{Methods}

Studies were done using fresh human gall bladder mucosa obtained at the time of elective 
cholecystectomy usually for gall stone disease. Patient's sex, age, and type of gall stones, if any, were recorded. The gall bladder tissue was retrieved within 15 minutes of the ligation of the cystic artery. A circular piece of the gall bladder wall $(\mathrm{d}=12 \mathrm{~mm})$ was removed using a tissue punch and placed in Ringer-Krebs glucose bicarbonate solution $(0.9 \% \mathrm{NaCl}(0.154 \mathrm{M})$, $1 \cdot 15 \% \mathrm{KCl}(0 \cdot 154 \mathrm{M}), 1 \cdot 22 \% \mathrm{CaCl}_{2}(0 \cdot 11 \mathrm{M})$, $2 \cdot 11 \% \mathrm{KH}_{2} \mathrm{PO}_{4}(0 \cdot 154 \mathrm{M}), 3 \cdot 8 \% \mathrm{MgSO}_{4} \cdot 7 \mathrm{H}_{2} \mathrm{O}$ $(0 \cdot 154 \mathrm{M}), 1 \cdot 3 \% \mathrm{NaHCO}_{3}, 5 \cdot 4 \%$ glucose $(0 \cdot 3$ $\mathrm{M})$ ) at $4 \mathrm{C}$ and preoxygenated with $95 \% 0_{2} .5 \%$ $\mathrm{CO}_{2}$. To minimise tissue hypoxia, this was done as soon as the gall bladder was removed.

The gall bladder tissue was transferred to the laboratory and within five minutes the mucosa was stripped by blunt dissection from the muscular part of the wall, rinsed with RingerKrebs bicarbonate glucose (RKGB) solution to remove debris and bile and mounted in an Ussing Chamber. The Ussing Chamber consisted of two $2 \mathrm{ml}$ volume compartments each of which communicated with a glass tube above through two plastic tubes (inlet and outlet) (Fig 1). The gall bladder tissue separated the two compartments creating a mucosal compartment at the mucosal site and a serosal compartment on the opposite side. The term 'serosa' is used throughout to indicate the non-luminal surface of the mucous membrane. Both compartments were filled with $10 \mathrm{ml} \mathrm{RKGB}$ through the glass tubes $(2 \mathrm{ml})$ in each compartment of the chamber and $8 \mathrm{ml}$ at each glass tube). The mucosal compartment was sealed while $95 \% \mathrm{O}_{2} / 5 \% \mathrm{CO}_{2}$ $(21 / \mathrm{min})$ was bubbled through to the serosal compartment only. Preliminary experiments had shown that $\mathrm{pO}_{2}$ between mucosal and serosal compartments did not differ significantly if $95 \%$ $\mathrm{O}_{2} / 5 \% \mathrm{CO}_{2}$ was bubbled into the serosal compartment only and this was preferred in order to avoid disruption of the 'unstirred water layer' in the mucosal side. ${ }^{20-21}$ The whole system was covered by a thermostatic water jacket to maintain a constant temperature of $37^{\circ} \mathrm{C}$ throughout

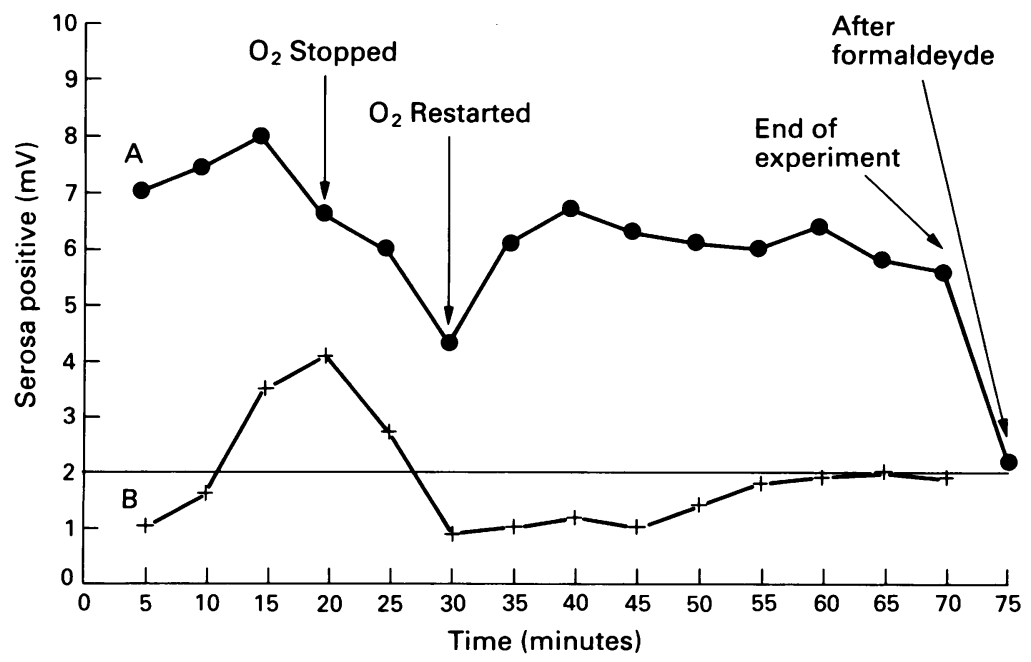

Figure 1: Potential difference across the human gall bladder mucosa; $(A)$ represents a viable gall bladder with an initial potential difference of $7 \mathrm{mV}$. Oxygen deprivation or immersion in formaldehyde resulted in a drop in the potential difference across the epithelium but recovered when oxygen was reintroduced. $(B)$ represents a gall bladder with an initial potential difference of less than $2 \mathrm{mV}$. Although potential difference recovered after 15 minutes, oxygen deprivation resulted in a non-reversible fall in the potential difference. Gall bladders with initial potential difference $<2 m V$ were excluded from further study. the experiment. A pair of silver/silver chloride matrix $1 \mathrm{~mm}$ electrodes (Clark Electromedical Instruments, Reading, Berks, UK) monitored the potential difference across the two sites of the tissue and used as an index of viability of the tissue. Each study lasted for 70 minutes. One millilitre of the solution was removed through a micropipette from each compartment of the Ussing Chamber at two minutes, 45 minutes and 70 minutes and was immediately analysed in an $1302 \mathrm{pH} /$ blood gas analyser (Instrumentation Laboratory System, Lexington, MA, USA) for $\mathrm{pO}_{2}, \mathrm{pCO}_{2}$, hydrogen ion $([\mathrm{H}+])$, and bicarbonate $\left(\left[\mathrm{HCO}_{3-}\right]\right)$ concentrations. Gall bladders which were macroscopically grossly distorted or damaged were excluded from further study.

\section{EXPERIMENTS}

Forty gall bladders were studied. The experiments were divided into three groups.

\section{First group}

Five gall bladders were studied. The effect of oxygen deprivation and immersion in formaldehyde $4 \%$ on the resting potential difference was observed. $95 \% \mathrm{O}_{2} / 5 \% \mathrm{CO}_{2}$ was bubbled at a steady flow rate of $21 / \mathrm{min}$ from time 0 to 20 minutes, then stopped for 10 minutes from time 20 to 30 minutes and subsequently continued at the same flow rate until the end of the experiment. Thereafter the gall bladder mucosa was exposed to $4 \%$ formaldehyde for two minutes, rinsed with RKGB solution and remounted to the Ussing Chamber and studied for further 10 minutes. The potential differences were monitored continuously throughout the experiment.

\section{Second group}

Twenty five gall bladders were studied. Twenty one were processed according to the standard protocol to maintain viability and four were immersed in formaldehyde $4 \%$ for two minutes before being mounted on the Ussing Chamber. The hydrogen ion concentration, bicarbonate concentration $\mathrm{pCO}_{2}$ and $\mathrm{PO}_{2}$ were measured at the beginning (two minutes) at 45 minutes and the end of the experiments ( 70 minutes). The resting transepithelial potential difference was monitored throughout. The aim was to study the acidification capacity of the viable gall bladder compared with non-viable tissue.

\section{Third group}

Ten gall bladders were studied. In the first set of experiments involving six gall bladders the mucosal bathing solution was replaced by sodium free Krebs-Ringer solution $(\mathrm{NaCl}$ and $\mathrm{NaHCO}_{3}$ removed) and the analytes mentioned above were measured. In a second set of experiments involving four gall bladders $2 \mathrm{mM}$ amiloride (a specific $\mathrm{Na}+/ \mathrm{H}+$ inhibitor) was introduced into the mucosal compartment and its effect on acidification was observed after 45 minutes. 

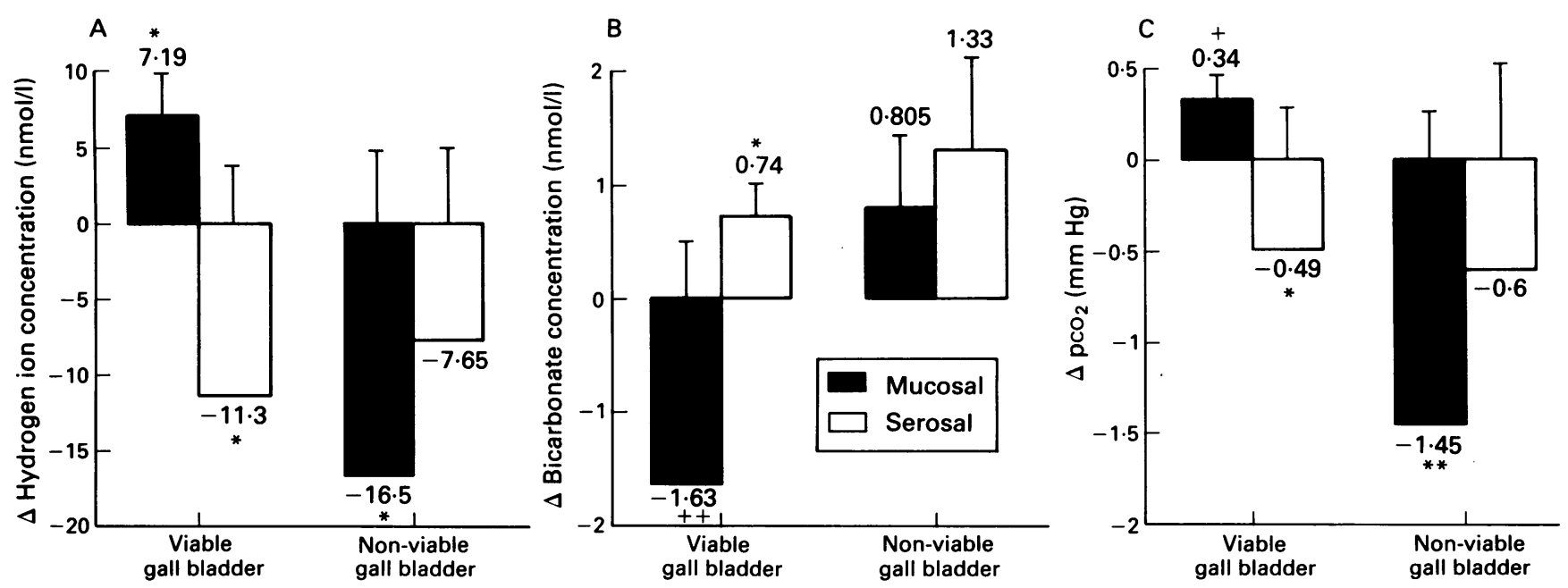

Figure 2: Differences in hydrogen ion concentration $(A)$, bicarbonate concentration $(B)$, and $p C \mathrm{O}_{2}(C)$ between 70 and two minutes in the mucosal and serosal side of the viable and non-viable gall bladders $\left({ }^{\star} p<0.05,+p<0.03,++p<0.02,{ }^{*} p<0.01\right)$.

\section{PATHOLOGY}

A small sample of the tissue under study was fixed in $10 \%$ buffered formalin before each Ussing Chamber experiment. The rest of the tissue was also fixed in $10 \%$ buffered formalin at the end of the experiment. An experienced histopathologist examined each gall bladder blindly on two occasions and reported on the degree of cholecystitis and the viability of the tissue according to cell morphology at the beginning and end of the experiments. The degree of cholecystitis was graded from 1 (mild) to 3 (severe) according to the appearance of the mucosa, muscle layer thickness, presence of Rokitansky-Aschoff sinuses and degree of inflammatory process. ${ }^{22}$ The morphology changes were recorded as 0 (healthy looking cells), 1 (mild morphological changes such as cell oedema, presence of granules, vacuolation), 2 (moderate but without evidence of cell necrosis).

The gall bladders used in the above experiments were selected according to the following criteria: (a) satisfactory macroscopic appearance with no obvious ulceration or fibrosis at the beginning of the study and no obvious damage during the study; (b) expression of a resting potential difference more than $2 \mathrm{mV}$ of serosa positive; (c) data from mucosa with severe changes in cell morphology were excluded from further analysis.

Figure 3: Differences in hydrogen ion secretion with histology (grade 1 (mild) to grade 3 (severe) cholecystitis) ${ }^{\star} p<0 \cdot 01$.

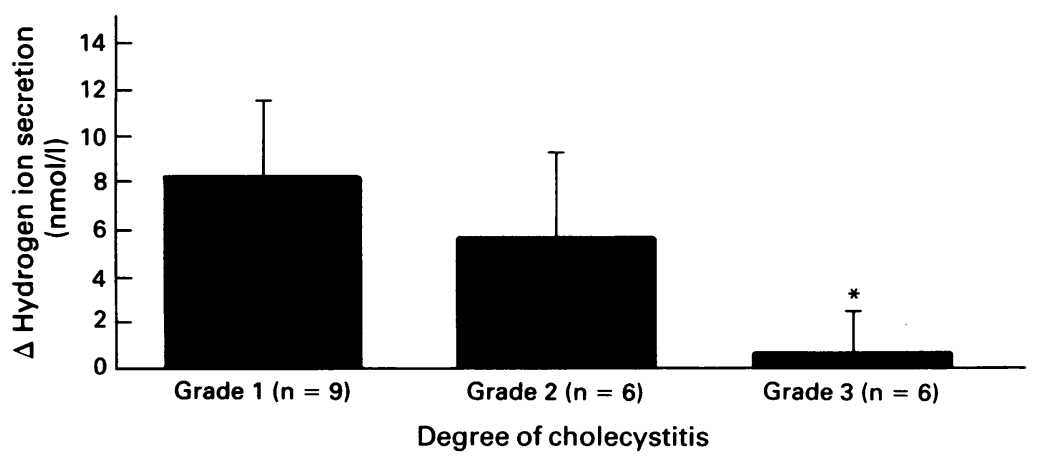

Data are expressed as mean standard error of mean (SEM). The data were not normally distri- buted and were analysed using non-parametric tests; Mann-Whitney test was used for unpaired data and Wilcoxon's test for paired data. A p value of 0.05 was taken as significant.

\section{Results}

In the first set of experiments the gall bladders (five) documented a mean potential difference of $7 \cdot 5 \pm 3.5 \mathrm{mV}$ serosa positive after five minutes in the chamber. This potential difference remained quite stable throughout the ensuing 15 minutes. There was a significant drop in the potential difference when $95 \%$ oxygen $5 \% \mathrm{CO}_{2}$ was discontinued, but when reapplied the potential difference recovered to levels similar to those before oxygen deprivation indicating that hypoxia had a direct effect on reducing the resting potential difference. When those gall bladders were immersed in formaldehyde $4 \%$ and remounted on the Ussing chamber, however, there was a dramatic and irreversible drop in the potential difference indicating nonviability of the tissue (Fig 1). The $\mathrm{pO}_{2}$ was measured in both compartments at two minutes, 45 minutes, and 70 minutes. Although $95 \% \mathrm{O}_{2} /$ $5 \% \mathrm{CO}_{2}$ was bubbled in the serosal compartment only, there was no difference in the $\mathrm{pO}_{2}$ between the mucosal and serosal compartment $(25 \cdot 3(2 \cdot 1)$ $\mathrm{pKa} v 23.5(2 \cdot 2)$ pKa respectively) which shows that the diffusion of oxygen through the gall bladder mucosa was adequate. It was thought therefore unnecessary to oxygenate the mucosal compartment directly, as this would disrupt the 'unstirred water layer'. All gall bladders showed evidence of chronic cholecystitis (three grade 1 , two grade 2) without any significant changes in cell morphology at the beginning and end of the experiments.

In the second set of experiments 25 gall bladders were studied ( 18 women, seven men; 13 contained cholesterol stones, nine pigment stones, three biliary sludge). Four of those were immersed in formaldehyde and used as controls and from the remaining 21 , six showed evidence of grade 3 chronic cholecystitis and were not included in the analysis outlined below. There was a significant increase in the hydrogen ion concentration from two minutes to 45 minutes 
and to 70 minutes observed in the mucosal compartment $(\mathrm{p}<0.01)$ while in the serosal compartment there was a significant decrease in hydrogen concentration $(p<0.05)$. By contrast in the non-viable gall bladder (those immersed in formaldehyde) there was a significant drop in hydrogen concentration on the mucosal site without any significant change of hydrogen concentration in the serosal side (Fig 2a). In the viable gall bladder bicarbonate concentration significantly decreased in the mucosal compartment from two minutes to 45 and 70 minutes $(p<0.02)$ while on the serosal side there was a significant increase of bicarbonate concentration from two minutes to 70 minutes. In the nonviable gall bladder an increase of bicarbonate concentration was seen in both compartments (Fig 2b). In the viable gall bladder there was a significant increase in $\mathrm{pCO}_{2}$ between two and 70 minutes on the mucosal site $(p<0.03)$ while in the serosal compartment a significant decrease in $\mathrm{pCO}_{2}$ was observed $(\mathrm{p}<0.05)$. In the non-viable gall bladder there was a drop in $\mathrm{pCO}_{2}$ in both compartments being significant in the mucosal side $(\mathrm{p}<0.01)$ (Fig 2c).

In the viable gall bladder the mean potential difference did not significantly change throughout the experiments. There was, however, a significant difference in the potential difference between the viable and the non-viable gall bladders studied $(6 \cdot 3(2 \cdot 6)$ to $1 \cdot 3(0 \cdot 9), \mathrm{p}<0.01)$ at five minutes. The potential difference of the non-viable gall bladders rapidly declined to 0 . When the acidification ability of the 21 gall bladders was plotted against the degree of chronic cholecystitis there was a progressive and statistically significant decrease of hydrogen ion secretion from grade 1 (mild) to grade 3 (severe) cholecystitis (Fig 3).

The same was true when hydrogen ion secretion was plotted against the degree of cell morphology changes graded from 0 to 2 indicating that gall bladder epithelia with impaired viability had a tendency to secrete less hydrogen ions (Fig 4).

There were no differences in the acidification capacity of the gall bladders with sex or type of gall stones, although epithelia from gall bladders with pigment stones had a higher ability to absorb bicarbonate $\left(\triangle\left[\mathrm{HCO}_{3}\right]=-1.68(0.49)\right.$ $\mathrm{mmol} / \mathrm{l}$ (pigment) $\mathrm{s} 3.8(0.74) \mathrm{mmol} / \mathrm{l}$ (cholesterol), $\mathrm{p}<0.01$ ).

In the third set of experiments (10) RKGB solution was replaced with sodium free isotonic solution in the mucosal side. No significant changes suggesting 'sick cells', grade 2: moderate changes without evidence of necrosis) ${ }^{\star} p<0.01$.

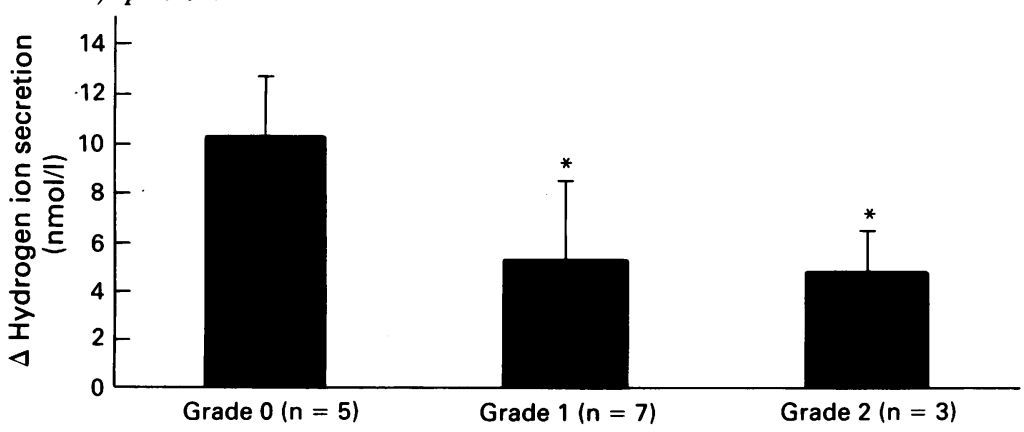

Degree of cell morphology changes

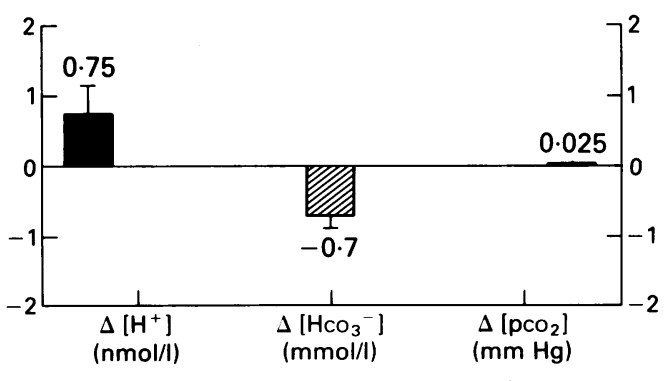

Amiloride $2(\mathrm{mmol} / \mathrm{l})$ (mucosal side) $(\mathrm{n}=4)$

Figure 5: Effect of mucosal application of amiloride (2 $\mathrm{mM}$ ) on hydrogen ion secretion.

differences in the $[\mathrm{H}+],\left[\mathrm{HCO}_{3-}\right]$ and $\mathrm{pCO}_{2}$ were observed in any site of the Ussing chamber, between two and 70 minutes of the experiment. Similarly, the use of amiloride ( $2 \mathrm{mM})$ in the mucosal side abolished acidification (Fig 5 ).

\section{Discussion}

The Ussing chamber method has been adapted and used by many investigators since its introduction by Ussing and Zerhan in $1951 .{ }^{23}$ It is a valid method of keeping a biological preparation viable during the period of investigation and has been used to study electrophysiological, secretory, and absorptive properties of tissues in vitro. Tissues previously used include frog skin, intestine, bladder, and animal and human gall bladder.

For years it has been known that gall bladder bile is more acid compared with hepatic and the difference in the $\mathrm{pH}$ has been attributed to bicarbonate absorption. ${ }^{15}$ In this study we have shown that fresh viable human gall bladder mucosa is capable of acidifying physiological solutions in vitro. This acidification is a function of viable tissue; it was reduced in more inflammed gall bladders or when the epithelial cells became 'sick' during the study and was lost when the mucosa was non-viable. Acidification was abolished when the gall bladder epithelium was exposed to. sodium free solution or in the presence of high concentration of amiloride in the mucosal compartment. In our study where human gall bladders were used to investigate acid secretion in vitro, the gall bladder epithelium appeared capable of increasing the hydrogen concentration in mucosal side with simultaneous decrease of hydrogen concentration in the serosal side which suggests that hydrogen ions were transferred from the serosal to mucosal side of the tissue. The concomminant decrease of bicarbonate concentration with increased $\mathrm{pCO}_{2}$ in the mucosal side indicates that this acidification is not simply the result of bicarbonate reabsorption. It appears that hydrogen ions produced by the mucosal cells react with bicarbonate to form $\mathrm{Co}_{2}$ and water with a decrease in bicarbonate ions. The observed differences in $\mathrm{pCO}_{2}$ between the viable and non-viable gall bladders could be explained on the basis that a non-viable gall bladder mucosa loses its ability to secrete acid therefore less hydrogen ions are available to react with bicarbonate and also that the production of $\mathrm{CO}_{2}$ from the mucosal cell metabolism is depressed.

Studies on gall bladders of other animal 
species such as rabbit, guinea pig, necturus, and dog have shown that these tissues are capable of acidifying the mucosal solutions in vitro and there is evidence that a sodium/hydrogen antiport is present at the apical site of the epithelial cell. In our experiments the use of sodium free solutions and amiloride, which is a specific sodium/hydrogen inhibitor, abolished acidification which suggests that hydrogen secretion in the human gall bladder depends upon a sodium/ hydrogen antiport.

A potential problem, with Ussing chamber studies is related to the viability of the tissue received at cholecystectomy. The ligation of cystic artery which is part of the operative procedure usually takes place between five to 20 minutes before the removal of the gall bladder. The effect of hypoxia during this period has been studied $^{2+}$ and about $70 \%$ of the gall bladders examined immediately after the operation showed evidence of mitochondrial change which was attributed to anoxia and mechanical damage. The human as well as animal gall bladder, however, is a durable organ which can rapidly recover from hypoxia and can be preserved viable for in vitro experiments for up to four hours.' The gall bladder has been used for many years as a model to study ion transport across the epithelia. In this study all the gall bladders showed a transmural potential difference of more than $2.3 \mathrm{mV}$ (range $2 \cdot 3-11.9 \mathrm{mV}$ ) serosa positive. This potential difference remained stable throughout the period of experiment and we, as well as other workers, ${ }^{25-27}$ were able to show that anoxia resulted in a drop at the transmural potential difference reflecting a reducing viability of the tissue which was reversible if the anoxic period was less than 10 minutes. Similar results were produced after immersion in formaldehyde with a permanent drop of the potential difference indicating loss of viability. The continuous transpotential difference monitoring therefore has been used as a reliable method of monitoring the viability of the tissue and allow further study of the mucosal function. The transmural potential difference of the gall bladders under study was in accordance with the literature. Ross and others ${ }^{25}$ carried out studies on the electrical properties of the human gall bladder and on 46 gall bladders the mean transpotential difference was $7.6 \mathrm{mV}$ while other investigators ${ }^{26}$ later showed that inflamed gall bladders have a lower resting transpotential difference which is dependent upon the degree of inflammation, the variation in time between the ligation of cystic artery, and the transfer to the laboratory and the methodology used for studying the electrical properties of the tissue. For instance, tissues which are clamped at the edges as in the Ussing chamber technique suffer from edge damage which reduces the transpotential difference. $^{27}$

Another potential problem with physiological studies using tissues from routine cholocystectomy is that most are not histologically normal. Although it is not appropriate to extrapolate to normal gall bladders in respect of hydrogen ion secretion, the fact that we could show changes in the acidification capacity with histology, the more inflamed gall bladders being less capable to secrete acid, implies that hydrogen ion secretion is a function of the normal human gall bladder mucosa. The acidification capacity was impaired when the cell morphology was abnormal and was abolished in the non-viable gall bladder; these suggest that hydrogen ion secretion is a function of a viable tissue. There is recent supportive evidence from animal and human studies that the normal gall bladder secretes acid. Moore $e t$ al showed that the canine gall bladder is capable of secreting hydrogen ions. ${ }^{18}$ Preliminary in vivo studies from the same group have shown that the diseased human gall bladder is associated with decreased acid output. ${ }^{28} 29$ Their conclusions, however, were not based on studies in human gall bladder mucosa directly, but were inferred from biochemical analysis of gall bladder biles from laparotomy.

Our data would support the hypothesis by Moore and colleagues that reduced gall bladder hydrogen ion secretion is associated with gall stone formation. It is postulated that the observed $\mathrm{pH}$ changes in our experiments with diseased gall bladders represent only a fraction of the capacity which the normal human gall bladder epithelium might possess to secrete acid. More studies on fresh normal tissue are required to test this suggestion.

It is now accepted that the sequence of events in the process of gall stone formation is supersaturation of bile, nucleation, precipitation, and subsequent growth to stone sized aggregates. ${ }^{30}$ Supersaturation of bile with cholesterol is present in the vast majority of patients with gall stone disease ${ }^{31}$; but 40 to $80 \%$ of normal individuals may have supersaturated bile without ever forming gall stones. ${ }^{32} 33$ Therefore the process of nucleation is important and this depends upon the presence of certain nucleating agents or the absence of the naturally occuring inhibitors of crystal formation.

Calcium bilirubinate or mucous glucoproteins could serve as nucleating factors ${ }^{34}$ while a bile protein which is a cholesterol crystal formation inhibitor has been proposed by Holzbach as a gall stone formation protective protein. ${ }^{35}$ Calcium has long been implicated in the pathogenesis of cholesterol and pigment gall stones. Pigmented gall stones are predominantly composed of the calcium salts of carbonate, bilirubinate, phosphate, and long chain fatty acids and to a lesser extent carbonate. ${ }^{36-38}$ Calcium carbonate also precipitates on to the surface of the cholesterol gall stones and is present in most cholesterol gall stones. ${ }^{8}$ The regulation of calcium concentration in the gall bladder bile is therefore of critical importance. It is postulated that acid secretion may be biologically important because a reduction in the $\mathrm{pH}$ of the gall bladder bile effectively lowers the bicarbonate and may reduce the risk of insoluble carbonate formation. As a result, the concentration of ionised calcium is increased in bile. The gall bladder epithelium, however, has the ability to absorb calcium and can reduce its concentration in bile by more than $50 \%{ }^{8}$; bile acids also buffer the remaining ionised calcium. Consequently less calcium is available to form insoluble salts. ${ }^{39}$

The mechanism of acid secretion also merits 
further investigation. In this study we have shown that it is sodium dependant, therefore it is closely linked with the concentrating ability of the gall bladder because it is known that water is passively absorbed consequent upon the absorption of sodium from the epithelial cell. It is, however, necessary to identify other factors which may influence acid secretion and further studies are under way to investigate this.

In conclusion we have shown in this study that the viable human gall bladder is capable of secreting acid. This acid secretion probably occurs through an apical $\mathrm{Na}+/ \mathrm{H}+$ exchange at the mucosal site of the gall bladder epithelial cell. This may represent a protective mechanism against calcium precipitation. Further studies are needed to investigate more fully the process and identify those factors which regulate acid secretion.

We would like to thank Dr P W Flatman, Dept Physiology for advising on the Ussing Chamber method, $\mathrm{Mr} \mathrm{B}$ White for his technical assistance and the surgeons and staff of $9 / 10$ and $7 / 8$ operating theatres, RIE for providing the gall bladders. We would also like to thank Mrs V Campbell for typing this manuscript. Dr J N Plevris is a recipient of William Gibson Fellowship, Faculty of Medicine, University of Edinburgh. This study was partly Medicine, University of Edinburgh. This study
supported by a grant from the Lothian Health Board.

1 Diamond JM. Cook CF, ed. Transport mechanisms in the gallbladder. Handbook of physiology: alimentary canal. Washington DC: American Physiological Society 1968 2451-82.

2 Diamond J. The mechanism of isotonic water transport. 7 Gen Physiol 1964; 48: 15-42.

3 Diamond J. Transport of salt and water in rabbit and guinea pig gall bladder. F Gen Physiol 1964; 48: 1-14.

4 Heintze K, Petersen KU, Olles P, Saverymuttu SH, Wood JR. Effects of bicarbonate on fluid and electrolyte transport by the guinea pig gallbladder: a bicarbonate-chloride exchange. the guinea pig gallbladder: a bicar

5 Rose RC. Absorptive functions of the gallbladder. In: Johnson LR, ed. Physiology of the gastrointestinal tract. Vol 2. New York: Raven Press, 1981; 1021-2.

6 Rege RV, Nahrwold DL, Moore EW. Absorption of biliary calcium from the canine gallbladder; protection against the formation of calcium-containing gallstones. $\mathcal{F} \mathrm{Lab}$ Clin Med 1987; 110: 381-6.

7 Jacyna MR, Ross PE, Bakar MA, Hopwood D, Bouchier IAD. Characteristics of cholesterol absorption by human gallbladder: relevance to cholesterolosis. 7 Clin Pathol 1987; 40 524-9.

8 Conter RL, Roslyn JL, Porter-Fink V, DenBesten L. Gallbladder absorption increases during early cholesterol ballstone formation. Am $\mathcal{F}$ Surg 1986; 151: 184-91.

9 Wood JR, Svanvik J. Gallbladder water and electrolyte transport and its regulation. Gut 1983; 24: 579-93.

10 Wahlin T, Thornell E, Jivegard L, Svanvik J. Effects of intraWahlin $\mathrm{T}$, Thornell $\mathrm{E}$, Jivegard $\mathrm{L}$, Svanvik $\mathrm{J}$. Effects of intra-
luminal prostaglandin $\mathrm{E} 2$ in vivo on secretory behaviour and ultrastructural changes in mouse gallbladder epithelium. Gastroenterology 1988; 95: 1632-5.

11 Lee SP, LaMont JT, Carey MC. Role of gallbladder mucus hypersecretion in the evolution of cholesterol gallstones. f Clin Invest 1981; 67: 1712-23.

12 Reuben A. Biliary proteins. Hepatology 1984; 4: 465-505.

13 Whitlock RT, Wheeler HO. Hydrogen ion transport by isolated rabbit gallbladder. Am F Physiol 1969; 217: 310-6.
14 Cremiaschi D, Henin S, Meyer G. Stimulation by $\mathrm{HCO} 3$ of $\mathrm{Na}+$ transport in rabbit gallbladder. $7 \mathrm{Membr}$ Biol 1979; 47: $145-70$.

15 Heintz K, Petersen KU, Wood JR Effects of bicarbonate on fluid and electrolyte transport by guinea pig and rabbit gallbladder: stimulation of absorption. $\mathcal{F}$ Membr Biol 1981 62: 175-81.

16 Weinman SA, Reuss L. $\mathrm{Na}+/ \mathrm{H}+$ exchange at the apical membrane of the necturus gallbladder. F Gen Physiol 1982; 80: 299-319

17 Altenberg G, Reuss L. Apical membrane $\mathrm{Na}+/ \mathrm{H}+$ exchange in necturus gallbladder epithelium. $\mathcal{F}$ Gen Physiol 1990; 95: 369-92.

18 Rege RV, Moore EW. Evidence for $\mathrm{H}+$ secretion by the in vivo canine gallbladder. Gastroenterology 1987; 92: 281-9.

19 Rege RV, Moore EW. Pathogenesis of calcium-containing gallstones. $\mathcal{F}$ Clin Invest 1986; 77: 21-6.

20 Diamond JM. A rapid method for determining voltage con centration relations across membranes. If Physiol 1965; centration relation

21 Diamond JM. Non-linear osmosis. F Physiol 1965; 183: 58-82.

22 Symmers W S-C. Systemic pathology. Vol 3. 2nd Ed. Edinburgh: Churchill Livingstone, 1978: 1304-30.

23 Ussing HH, Zerhan K. Active transport of sodium as the source of electric current in the short-circuited isolated frogskin. Acta Physiol Scand 1951; 23: 110-27.

24 Hopwood D, Kouroumalis E, Milne G, Bouchier IAD Cholecystitis. A fine structural analysis. I Pathol 1980; 130: 1-13.

25 Ross RC, Gelarden RT, Nahrwold DL. Electrical properties of isolates human gallbladder. Am $\mathcal{F}$ Physiol 1973; 224: 1320-6.

26 Nahrwold DL, Ross RC, Ward SP. Abnormalities in gallbladder morphology and function in patients with bladder morphology and function in
cholelithiasis. Ann Surg 1976; 184: 415-21.

27 Jacyna MR. Aspects of mucosal function in the human gallbladder. 1986: 108-10 (Thesis). University of Dundee, Scotland.

28 Moore EW, Shiffman ML. Evidence of $\mathrm{H}+$ ion secretion by the human gallbladder in vivo. Gastroenterology 1988; 95 A573.

29 Shiffman ML, Moore EW. Defective acidification leads to $\mathrm{CaCo}_{3}$ supersaturation of gallbladder bile in patients with all types of gallstones. Gastroenterolog $v$ 1988; 94: A591.

30 Smith BF, Lamont JT. The sequence of events in gallstone formation. Lab Invest 1987; 56: 125-6.

31 Admirand WH, Small DM. The physiochemical basis of cholesterol gallstone formation in man. $\mathcal{F}$ Clin Invest 1968 ; 47: 1043-52

32 Holzbach RT, Marsh M, Olsweski M, Holan K. Cholesterol solubility in bile. Evidence that supersaturated bile is frequent in healthy man. 7 Clin Invest 1973; 52: 1467-79.

33 Hofman AF, Grundy SM, Lachin JM, Lan SP, Baum RA Hanson RF, et al. Pretreatment biliary lipid composition in white patients with radiolucent gallstones in the National Cooperative Gallstone Study. Gastroenterology 1982;83: 738-52.

34 Burnstein MJ, Ison RG, Petrunka CN, Taylor RD, Strasberg SM. Evidence of a potent nucleating factor in the gallbladder bile of patients with cholesterol gallstones. Gastroenterologv 1983; 85: 801-7.

35 Holzbach RT, Kibe A, Thiel E, Howell JH, Marsh M Hermann RE. Bilieary proteins. Unique inhibitors of cholesterol crystal nucleation in human gallbladder bile. cholesterol crystal nucleation

36 Sutor DJ, Wilkie LI. Calcium in bile and calcium salts in gallstones. Clin Chim Acta 1977; 79: 119-27.

37 Been JM, Bills PM, Lewis D. Microstructures of gallstones. Gastroenterology 1979; 76: 548-55.

38 Wosiewitz U. Limy bile and radiopaque, calcified gallstones: combined analystical, radiographic and micromorphologic examination. Pathol Res Pract 1980; 167: 273-86.

39 Moore EW, Celic L, Ostrow JD. Interactions between ionised calcium and sodium Taurochelate: bile salts are importan buffers for prevention of calcium containing gallstones. Gastroenterology 1982; 83: 1079-89. 